\title{
Bridging the Gap Between Industry and Higher Education Demands on Electronic Graduates' Competencies
}

\author{
Abdul Ghani Kanesan Bin Abdullah ${ }^{1}$ \\ ${ }^{1}$ School of Educational Studies, Universiti Sains Malaysia, 11800 Penang
}

\begin{abstract}
Full employment is an important objective for the nation's economy. Unfortunately, the impacts of active short-term labour market policies implemented by the Malaysian government that focus directly on the employment appear to be limited. Therefore, this study intend to find the gap of the employed electronic engineers meeting the demands required competencies of the electronic industry and the higher education In this paper, the gap was studied in two aspects, acquired and required competencies needed by the employer as well as higher education. Qualitative semi structured interview techniques was used to get data from the respondents. A total numbers of 10 lecturers, 13 employers (3 production, testing, or quality assurance engineers, 5 technical managers and 5 training manager or human resource managers from 8 different electronics firm), 12 employed electronic graduates, and 11 unemployed electronic graduates. The results shows that managers feel that there is a mismatch of competencies. They are dissatisfied with acquired knowledge of engineers. Only a small number is well equipped. Employers pay attention to quality rather than quantity. Interviews with the lectures showed that the graduates lack soft skills. Employed graduates too feel that soft skills are important in working environment. In acquired competencies, lectures from science and other professional courses believe that close to $80 \%$ graduates are equipped to handle real work tasks compared to only $50 \%$ of graduates from social sciences and arts courses. This study suggests that the gap in required and acquired competencies should be emphasized in curriculum design.
\end{abstract}

Keywords: Industry, Higher Education, Electronic Graduates Competencies

\section{INTRODUCTION}

In the pursuit of full employment, the Malaysian government has focused on the need to create a favorable investment climate in order to attract more foreign and domestic investment to generate employment opportunities to reduce the level of unemployment. The National Labour Policy (NLP), launched in 1992, came at the heel of the National Development Policy (NDP) with its emphasis on turning Malaysia into an industrial country by the year 2020. The NLP emphasizes on the need to ensure full employment [1]. But, there is no active labour market policy in the form of employment creation by the public sector either through direct job creation or employment subsidies. The only occasion in which the Malaysian government instituted an active short term policy (ASTP) in terms of employment creation was during the recession of mid-1980s when it creates temporary jobs with reduced allowance for some 4,000 unemployed graduates in public sector agencies [2].

In line with the NLP's recognition of the need to create a highly skilled and trained workforce that is capable of adapting to changes in the work environment brought about by technological changes, the Human Resource Development Council (HRDC) was established in 1993. The responsibility of the HRDC is to encourage private sector involvement on training and retraining of employees. The activities of the HRDC were initially confined to the manufacturing sector, but have been, since 1995, extended to include the training of employees in the service sector. The activities of the HRDC are directed primarily to the continuous provision of training in information and communication technology (ICT) [3]. There are two purposes for continuing training and retraining, firstly to improve the labour productivity and secondly to meet the demand for acquiring specific skills. Active long-term policy in meeting the challenges of globalization, liberalization and technological change come in the form of producing more science, technical and engineering graduates. Malaysia recognizes the need to create a highly skilled and trained workforce that is capable of adapting to changes in the work environment which brought by technological changes in labour market [4]. Importunely, the impacts of active short-term labour market policies implemented by the Malaysian government that focus directly on the employment appear to be limited. This transition mechanism appears to be gaining favor, concentrating on increasing the efficiency of the labour market. As for the employment, the manufacturing sector which is the largest sector of the skilled labour shows a slower employment growth due to the improved capital-labour ratio and efficiency in the production process. Therefore, the main demand will likely to focus more on highly skilled labour as the sector will move more towards value-added products and capital intensity [5]. Therefore, this study explores various competencies that are required by the electronics engineers especially in understanding the core elements constituting to competencies. Thus, the findings of the studies, 
would serve as a guide to integrate the required elements of competencies in electronics industries into the curriculum and the activities planned in the higher institutions.

\section{DEMANDS ON ELECTRONIC GRAdUATES' COMPETENCIES}

Universities are the places where specialized human resources are developed and access to university education is an indicator of a country's production of skilled personnel [6,7]. An increase in economic growth and development implies Malaysia's desire to increase resilience and competitiveness of the economy. In fact, labour productivity can be raised through improvements in the quality and quantity of education and training, including constant skills upgrading and lifelong learning [8,9]. However, for education and training to be successful in raising productivity, there is a need to focus on the internal and external efficiency of education and training programs [10]. Failure to focus on internal and external efficiency can be a result of the mismatch in the supply of graduates in the industrial and services sector. Likewise, it will be a result in the supply of graduates that may not be suitable for the job market, and thus can contribute to increase the levels of unemployment [11]. Even if graduates in the required area are produced, there is a great need to focus on the area of skills and competencies. Therefore, there should be a match between available skills of workers, and existing and new work opportunities in the industrial and services sector [5].

Further, there is a tendency for the graduates produced in a particular field each year to correspond to the number of employed opportunities in the particular field. Therefore, there is a tendency for the graduate to be unemployed because of the area of study, or obtaining a CGPA below the required level identified by the industries [5]. The other possible cause is the competencies level acquired by the graduates may not meet the requirement of the employer. There are two possible reasons. One would be the employer may not be convinced by the acquired competencies of the graduates during the interview. Another possible reason is the employer may view that the graduates may be employed because they show high potential to develop the required competencies after recruitment through in house training [8]. However, at the time the new graduates get the opportunity to be placed in the respective tasks and workplace, they need more time to acquire new skills in order to become independent workers. The employer may have to provide extra allocation on the job training and off the job training. Inevitably, this may slowdown the process of getting an efficient output unit. Meanwhile, it would be unfavorable to the employers if the excessive training and retraining are needed which will add to the production cost, and making the industries less competitive [12].

Competencies are the ability to accomplish a task. Competencies can be divided into generic (soft) and subject specific (hard) competencies. Generic (soft) competencies are related to skills and knowledge commonly possessed by the general public [12]. These are not occupationally specified and considered applicable in more than one context. The main categorization of such skills in the study includes personal qualities, critical thinking skills, interpersonal skills, communication skills, ICT skills and management skills. These two skills operate in the cognitive and affective domains. Subject specific (hard skills) competencies are acquired through the curricula which are exclusive to a particular discipline. These are discrete components of the knowledge and skills that are discipline specific, and are academically relevant and form the basis for professional preparation and development. Knowledge and skills can be learned through a particular program. As in the case of electrical and electronic engineers, subject specific skills refer to those abilities which allow individuals to participate in the occupation more effectively and they can be categorized as technological skills and subject knowledge [13]. According to [10], the required competencies related to workplace demands are divided into two large components, generic competencies and subject-specific competencies. There are six groups of skills and competencies recommended in the model. In this research, the generic competencies component take into account the Global and Strategic, Industrial, Humanistic skills and competencies.

\section{Aim Of The Study}

The study intend to find the gap of the employed electronic engineers meeting the demands required competencies of the electronic industry and the higher education In this paper, the gap was studied in two aspects, acquired and required competencies needed by the employer as well as higher education

\section{Methodology}

A total numbers of 10 lecturers, 13 employers (3 production, testing, or quality assurance engineers, 5 technical managers and 5 training manager or human resource managers from 8 different electronics firm), 12 employed electronic graduates, and 11 unemployed electronic graduates. The purposive sampling was utilized when selecting the participants.

Data was collected through face-to-face interviews with all the participants. The data of the interviews were organized around several key issues pertaining to employers needs, graduates and university lectures views about current employers' needs and employability criteria Interviews were audio-taped and transcribed. Semistructured interactive interviews were used for this exploratory and descriptive qualitative study. Thematic 
analysis [14] was used to examine the data. Coding was conducted on transcribed interviews that described participants' experience.

\subsection{Acquired Soft Skills}

\section{Findings}

Most of the lecturers' indicate that the current graduates are not fully equipped with the necessary soft skills to survive in the working fields. Some of the areas identified by the lecturers are communication skills, expressing ideas, putting ideas across, English proficiency, problem solving, perform tasks independently, work in a group, and social skills. A pharmacy lecturer expressed concerned over students' soft skills ability especially pertaining to communication aspects. "Most of the students lack communication skills and are very poor in their command of the English language and unable to hold a conversation in English", he said. In the focused interviews with the managers in the electronic industry, 7 respondents expressed their views on the "ability to converse fluently in English". Among the interviewers, one production manager viewed the overseas graduates as the group with better command of English. He further attributed that to the advantage of different exposure of these graduates during their study. English is a global language and naturally an important tool to deal with global communications.

Some lecturers view soft skills such as presentation, marketing own self, analytical ability, and self confidence as a crucial components in the work places. However, an education lecturer points out that "We may have done a lot of work in the university but students may still lack in these areas due to biological reasons such as their innate character of being timid and the manner they may have to conform to their own culture may hamper progressive character portrayal". In fact, the same lecturer added that, "Some may see portrayal of certain out going character as excessive and cannot be tolerated." On the other hand, a timid, excessive humble attitude may be perceived as a weakness of employee in the area of soft skills. "Asian students are very passive." the manager commented.

Most employers agree that, soft skills are important to execute daily tasks among graduates. They believe that all graduates must acquire a certain level of soft skills competencies before entering the job market. A company human resource officer said, "The graduates need high level soft skills and in addition they must have leadership and problem solving skills in order to overcome daily obstacle without external help." Another company manager stressed that soft skills must couple with good personality. "Good attitude is very important, we can provide the world's best trainer, and training materials but if the attitude of graduate is bad all will be useless", he said.

Most of the employed graduates acknowledge the fact that, the soft skills are needed in their work environment. Based on their views the soft skills, such as communication, portrayal of positive image, good attitude, motivated, networking, and creativity, are important. Likewise, one employed graduate mentioned that, "Able to understand instruction and able to carry it out creatively is important." Furthermore, "Cooperation, responsible, positive thinking, and cheerful are important when completing a task", said another employed graduate. Similarly, one unemployed graduate highlights that, "Interpersonal skills should be greatly emphasized."

\subsection{Acquired Competencies}

University electronic and electrical engineering lecturers were interviewed concerning the acquired competencies of the engineers in the electronic industry. One lecturer comments that the local public university has a different role to play to cater for overall demand of the industry. Therefore, the curriculum was designed for the related field and not focused on a particular area for the need of the particular sector. He commented that the curriculum design needs to take into consideration the needs of the students for further degree programs.

Most of the university lecturers interviewed believed that university education is able to meet the demands and needs of the industry. For example, most lecturers believed that science and other professional graduates are close to $80 \%$ equipped to handle real time work tasks as needed by the industry. However, lecturers from the social sciences and arts believed that graduates are at least $50 \%$ equipped to deal with demands and needs of the industry.

Many lecturers expressed concern over students' attitudes, personality and time in order for university education to achieve its maximum output potential. An industrial science lecturer voices her concern over students' attitude, "Our school does offer a variety of non registered courses such as research method and career guidance, how to write good curriculum vitae, how to prepare for interviews; however, only a handful of students are interested in this courses."

In terms of personality, apparently some biological and cultural traits are still prevalent among university students. For example, an education lecturer often saw laid back attitude among some of the students. Some permanent cultural traits, such as laid back and less aggressive attitude are not easy to be removed. However, she feels that if university students concentrate more on what they are doing, they will be able to do it 
successfully. Lecturers do voice their concerns about time factor. Housing and planning lecturer said, "They hardly had any time to think except to follow the flow and what others are doing." He feels that students have way too many subjects to complete and have little or no time to develop other necessary skills that are required by the industry.

Many employers indicate precisely that university should focus more on practical knowledge and experience, as opposed to theoretical knowledge. They recommended that universities must provide courses which are relevant and can be matched with the market needs. One company manager suggests that, "Making industrial training as a compulsory course in the university". However, some of the employers disagreed; and they believed that knowledge acquisition is an on-going process and what is most important in this respect is that graduates must be willing to learn. "They will collect the experience and knowledge little by little", said one manager. In the focused interviews, managers expressed their appreciation of industrial training in exposing the undergraduates to the real work environment. This is especially essential during the participation of undergraduates in the electronic projects management. However, they complained that the time frame given was too short.

Both employed and unemployed graduates commented that university education must allow graduates to obtain more work related skills. Work knowledge, if possible, must be included in the teaching and learning process. One employed graduate suggests that, "A course about certain types of work should be introduced as a subject matter in the university and this will enable graduates to simultaneously perform practical training in a more comprehensive manner."

Most unemployed graduates meanwhile, argue that their results are relatively poor and lacking in expected work knowledge. One unemployed graduate said, "Working world is entirely different from students' world." While another unemployed graduate requested that university should do more to assist graduates to find work in the job market. "University should do a special briefing pertaining to job availability and conduct relevant help to secure the job", she said.

\subsection{Existence of the Gap}

Focused interviews with the managers (employers) of the electronic industry give a picture of the mismatch. From the analysis of the interviews, it was clear that the respondents agreed that the gap, or mismatch, of the competencies exists. Several respondents illustrate how this mismatch posted a problem for them. Generally, the managers were dissatisfied with the acquired knowledge of the engineers. Knowledge acquired by the electronic engineers was not really applicable and only a small number of the recruits fulfilled the competencies required. However, this small number of well-equipped engineers becomes the most favorable and pursued candidates by most companies. This is in line with the possible reasons of unemployment. Vacancies of the employment are there, but no suitable candidates for the job. One human resource manager quoted, "...75\% just fill up the numbers. Many companies are going after this $25 \%$..."

This pointed to the mismatch of the required competencies and the acquired competencies. The results indicate that many employers pay serious attention to the quality of the engineers rather than quantity. When further probed into the categories of the soft and hard competencies, feedback from these interviews provided some results that deficiency in the soft skills (generic skills) in the electronic industry (non-resource based sector) is more serious than subject specific skills .

For the respondents who did not explicitly address the gap of the skills and knowledge acquired and required, they expressed their dissatisfaction with the acquired competencies of the electronic engineers, for example a manager stated, "Hard to find (suitable candidates)".

These affirmative consensus about the gap induced further illustration on the impact of the competency mismatch. A training manager admitted that the gap caused problems to them, and the HR manager from the same firm supported the statement by revealing that the output (competency of the engineers) was "Not matching". The non satisfaction of the acquired competencies of engineers was expressed by a senior industrial engineer of a company and the Engineering Manager of another company. One senior engineer said that "Suitable candidates are hard to get."

With the limitation of finding suitable candidates, many firms engage the alternative by taking in candidates with potential and run training programs for these recruits. However, this alternative incurred higher costs and reduces profit margins. A training manager from an MNC company stated that given sufficient training time, the recruits will learn the necessary skills and knowledge. However, it was said that training provided will be easier if one is equipped with certain soft skills. This further strengthens the notion of a greater demand for generic skills rather than the hard skills.

\section{Conclusion And Implication}

Identification of the required hard skills and soft skills were completed through the process of qualitative analysis. The soft skills identified were found to be repeatedly emphasized by respondents (employees and 
employers) during the interviews. In addition, the respondents also indicated that the required competencies were changing dramatically. These changes were greatly motivated by the business environment factors and technological changes.

The changing role of the manufacturing and service sector environment resulted in the need and quest for soft skills competencies to increase. The roles of communication skills and interpersonal skills were more emphasized in the present career. The traditional role that only focused on the technical/content knowledge has undergone changes as a result of the impact of the business environment and technological changes. The keen competition in the business and services world raised the demand for employees to equip themselves with soft skills such as communication skills and interpersonal skills. The changes of the business environment demand them to interact with vendors, suppliers, customers and to solicit information and feedback within and between departments. Teamwork is required whether in troubleshooting or discussing work procedures. In such situations, communication skills are needed for the proper delivery of messages. Furthermore, the employees are required to prepare reports, present ideas, discuss results of testing, and make effective explanation to customers or vendors. Under these situations, proper techniques of discussion involving skills to negotiate and flexibility in handling discussion become the key points to the successful communication.

The present research has indicated that the is a gap, exists between the acquired and required competencies of employees (electronic engineers). Acquired competencies do not answer the needs for required competencies in the industrial and services operation. The gap needs to be addressed by the tertiary education system and the industry. The gap has caused a problem to the industry operators. The industry normally tackles the problem of competency mismatch by offering training to the graduates. However, this was not deemed as a favorable option as the productivity of employees will not be fully utilized. Learning curves takes time. Furthermore, enhancement of soft skills is difficult to be materialized in a short time. Some employers' quest for well-equipped workforce with good soft and hard skills creates another problem of 'talent-hunt' and this would result in greater cost for human resources. This complicates the search for the right candidate for the right job; consequently, and the gap continues.

Employers were more concerned with the gap in the area of soft skills. The quantitative analysis confirmed employers' worries. As for the hard skills category, the only category having a critical mismatch was quality, reliability and testing. It is the category that was among the most required hard skills competency but unfortunately it was least acquired. Quality and reliability issues were closer related to the customers' satisfaction. Factors in business environment greatly influenced the required competencies of employees; therefore, enhancement in the area of hard skills is necessary and urgent. Furthermore, the hard skills related to 'quality, reliability and testing have to emphasize on the curriculum design because it is much related with ISO 9000 and ISO 1400. Through such courses, it would give an alternative to strengthen the undergraduates' understanding towards quality and systems.

Current Malaysian universities curricula show the development and progress of curricula design in taking account of the market demand. Soft skills (humanistic, management, communications, ethics) are being emphasized and more credits hour allocated. Emphases have been made in the area demanded by the market (employment). Among the area of emphasis made are personalities, effective communication, high standard of ethical conduct, lifelong learning, and teamwork. Industrial training is given high priority too so that the graduates can be competence for employment in the industry. Undergraduates are urged to achieve innovation in the knowledge construction. They are driven to be leaders and dynamic in their activities. These are the pressure applied to bring close the gap between tertiary education and employment.

\section{REFERENCES}

[1] INTAN, Malaysian development Policies (Kuala Lumpur, 2004)

[2] M.Lee, Higher education, in K.S. Jomo, and Ng Suew Kiat (Ed.), Malaysia economic development: Policy and reform,( Petaling Jaya: Pelanduk Publisher.1996) 317-340.

[3] W.K. Chen, and L.T. Chang, A study of Entry-level Employment Technological Competencies for the Junior College Graduates Majoring in Electronics Engineering, Proceeding World Conference on Engineering Education, Career Education, 1995, 56-61.

[4] C.S. Buan, and L.K. Hock 1995. Introduction, in Chew Sing Buan, Lee Kiong Hock \& Quek Ai Hwa (Ed.), Education and work: Aspirations of Malaysian secondary school students,( Kuala Lumpur: Universiti Malaya,1995) 1-13

[5] A. Pandian, University curriculum: An evaluation on preparing graduates for employment( National Higher Education Research Institute, Universiti Sains Malaysia, Penang 2005).

[6] R. Barnett, Improving higher education: Total quality care(Buckingham: SRHE \& Open University Press, 1995).

[7] N. Bennett, E.J., Dunne, and C. Carré, Patterns of core and generic skill provision in higher education. Higher Education, 37(1), 1999, 71-93

[8] T. Chevaillier, Higher education and its clients: institutional responses to changes in demand and in environment. Higher Education, 33(3),2002, 303-308

[9] D. D., Dill, and B. Sporn, The Implication of a Postindustrial Environment for the university: An Introduction, in D. D. Dill, \& B. Sporn (Ed.), Emerging patterns of social demand and university reform: Through a glass darkly (Oxford: IAU Press Pergamon, 1995) 1-19.

[10] B.Little, Reading between the lines of graduate employment. Quality in Higher Education, 7 (2), 2001,121-129 
[11] J. Warn, and P., Tranter, (2001) Measuring quality in higher education: a competency approach. Quality in Higher Education, 7(3), 2001, 191-198

[12] E. Dunne, N., Bennet, and C Carré, 2000. Skill development in higher education and employment, in F. Coffield, (Ed.), Differing visions of a learning society. Research findings, (The Policy Press \& ESRC,2000), 34-42

[13] L. Morley, 2001. Producing New Workers: quality, equality and employability in higher education. Quality in Higher Education, 7 (2), 2001,131-138

[14] M.B., Miles, and A.M. Huberman, 1984. Qualitative data analysis: A sourcebook of new methods. (Beverly Hills: Sage Publications, 1984). 